\title{
Bioindicadores Microbiológicos para Indicação de poluição Fecal
}

\author{
Microbiological Bioindicators for Indication of Fecal Pollution \\ Bioindicadores Microbiológicos para Indicación de contaminación Fecal \\ Gabriela Felismino de Andrade ${ }^{1 *}$, Daniela Bomfim de Barros².
}

\begin{abstract}
RESUMO
Objetivo: Discorrer sobre o uso de bioindicadores do grupo coliformes, evidenciar sua empregabilidade e características ideais para sua utilização, como também identificar o microrganismo que atende os padrões desejados. Resultados: Entende-se que a ineficiência de saneamento básico, políticas ambientais e socioeconômicas, conciliadas com a utilização da água contaminada, a alimentação e a higiene precária da população, ocasionam patologias provocadas por microrganismos advindos de poluição fecal. Devido ao declínio dos recursos hídricos, na busca de avaliações que constatem a qualidade da água para consumo e recreação, são utilizados bioindicadores microbiológicos do grupo coliformes presentes em grande número em fezes de humanos e animais homeotérmicos afim de verificar se aquele recurso hídrico sofreu contaminação de origem fecal. Conclusão: Foi compreendido que o uso de indicadores microbiológicos, é a maneira mais acessível e de rápida certificação na identificação de contaminação fecal, sabendo que a Escherichia coli é a bactéria do grupo que mais atende e satisfaz os requisitos de avaliação de qualidade da água.
\end{abstract}

Palavras-chave: Escherichia coli, Coliformes, Bactérias, Água.

\begin{abstract}
Objective: To discuss the use of coliform group bioindicators, highlight their employability and ideal characteristics for their use, as well as identify the microorganism that meets the desired standards. Results: It is understood that the inefficiency of sanitation, environmental and socioeconomic policies, combined with the use of contaminated water, food and poor hygiene of the population, because pathologies caused by microorganisms arising from fecal pollution. Due to the decline of water resources, in the search for assessments that verify the quality of water for consumption and recreation, microbiological bioindicators of the coliform group present in large numbers in feces of humans and homeothermic animals are used in order to verify if that water resource suffered contamination of water. fecal origin. Conclusion: It has been understood that the use of microbiological indicators is the most accessible and rapidly certifying way to identify faecal contamination, knowing that Escherichia coli is the bacteria in the group that best meets and meets the requirements for water quality assessment.
\end{abstract}

Keywords: Escherichia coli, Coliforms, Bacteria, Water.

\section{RESUMEN}

Objetivo: Discutir el uso de bioindicadores de grupos coliformes, resaltar su empleabilidad y características ideales para su uso, así como identificar el microorganismo que cumple con los estándares deseados. Resultados: se entiende que la ineficiencia de las políticas de saneamiento, ambientales y socioeconómicas, combinadas con el uso de agua contaminada, alimentos y la mala higiene de la población, causan patologías causadas por microorganismos derivados de la contaminación fecal. Debido a la disminución de los recursos hídricos, en la búsqueda de evaluaciones que verifiquen la calidad del agua para consumo y recreación, se utilizan bioindicadores microbiológicos del grupo de coliformes presentes en grandes cantidades en heces de humanos y animales homeotérmicos para verificar si ese recurso hídrico sufrió contaminación del agua. origen fecal Conclusión: Se ha entendido que el uso de indicadores microbiológicos es la forma más accesible y de certificación rápida para identificar la contaminación fecal, sabiendo que Escherichia coli es la bacteria del grupo que mejor cumple y cumple con los requisitos para la evaluación de la calidad del agua.

Palabras clave: Escherichia coli, Coliformes, Bacterias, Agua.

${ }^{1}$ Faculdade Internacional da Paraíba (FPB), João Pessoa - PB. *E-mail: danielabbarros@outlook.com

SUBMETIDO EM: 6/2019

ACEITO EM: 7/2019

PUBLICADO EM: 9/2019

REAS/EJCH | Vol.Sup.34 | e1099 | DOI: https://doi.org/10.25248/reas.e1099.2019 Página 1 de 7 


\section{INTRODUÇÃO}

A água é uma substancia natural, liquida e incolor. É responsável pela formação de lagos, rios, mares e oceanos. Para os seres humanos a água, em especial, a doce, é responsável por uma série de garantias. Ela assegura a saúde e a manutenção da vida, assim como provêm mudanças climáticas, produção de oxigênio, conservação do ecossistema do planeta e também mantem a vida de plantas e animais (RIBEIRO LGG e ROLIM ND, 2017).

Mesmo tratando se de um recurso restrito, a água doce fornece diversas aplicações econômicas, sendo ela matéria prima em industrias, agricultura, insumos, práticas de esporte, lazer e geração de energia. Para a vida humana, a Organização mundial da saúde (OMS), estipula que o uso necessário para cada indivíduo possuir uma vida saudável, seja de no mínimo $1,500 \mathrm{~m}^{3}$ de agua potável, significando assim um valor considerável de 9 trilhões de $\mathrm{m}^{3}$ ao ano só para consumo humano. Segundo dados da conferência internacional sobre água doce em Bonn 2001, 1,2 bilhões de pessoas vivem sem os parâmetros necessários de agua potável para manutenção da saúde e dignidade, 2,3 bilhões não possuem tratamento sanitário como rede de esgoto e 4 milhões de crianças morrem de doenças relacionadas a água de má qualidade todos os anos (GOMES JL e BARBIERI JC, 2003).

Calcula-se que $10 \%$ do volume de afecções de todo o globo seja proveniente de agua contaminada, mediante fatores ambientais (CONFALONEIRE U, et al., 2011). Sabendo- se que saúde não se determina apenas com ausência de doença, mas sim pela existência de vários outros fatores como moradia, transporte, meio ambiente, saneamento básico, educação, alimentação, trabalho, lazer e o acesso a bens e serviços essenciais, como diz a lei orgânica de saúde. A saúde das populações é dependente de ações setoriais com ênfase no saneamento e no meio ambiente, fazendo necessária a obrigatoriedade do estado em exercer essas condições ao coletivo (BRASIL, 2015).

Para Golveia N (1999) a degradação do meio ambiente, tem se agravado em países pobres e subdesenvolvidos, onde a população cresce desordenadamente, sem planejamento, controle social e financeiro. Nestas cidades, investimentos monetários e administrativos que possibilitam serviços de infraestrutura, saúde, moradia, emprego, segurança e controle ambiental se tornaram ineficazes. Levando assim populações periféricas e menos privilegiadas a enfrentar o que diz o autor "o pior dos dois mundos", estando expostos a problemas ambientais associados ao desenvolvimento econômico e sanitário típicos do subdesenvolvimento. Podemos considerar também, a carência de leis que garantam a proteção de ecossistemas. Enquanto países desenvolvidos possuem legislações ambientais que asseguram o controle ambiental, países subdesenvolvidos possuem leis mais brandas e até inexistentes.

A maioria dos problemas sanitários que afetam a população estão altamente ligados a fatores ambientais, e às condições inadequadas de saneamento básico (RIBEIRO JW e ROOKE JMS, 2010). Considerando que o predomínio de infecções por microrganismos relacionados a água é um dos indicadores do poder socioeconômico de uma população e pode estar associada a diversos determinantes: falta de saneamento básico e instalações sanitárias, a má atenção em cuidados com alimentos a serem ingeridos, a contaminação da água por coliformes fecais, além da idade do infectado e microrganismo infectante (BELO VS, et al, 2012).

Segundo DENZE AP e VERCELLINO IS (2018) o padrão de qualidade da água foi criado em 1975, com o objetivo de avaliar a substância em sua forma bruta para a potabilidade humana, porém apresentava deficiências, todavia que não analisava outros parâmetros essenciais como contaminantes tóxicos, microrganismos patogênicos e substancias que interviam no padrão de consumo da água.

Compreendendo que o consumo da água é indispensável a vida humana, entende-se que, manter a qualidade desse recurso é questão de saúde pública, visto que a água de má qualidade e exposta a contaminadores patogênicos podem causar doenças e até a morte dos indivíduos sem acesso a água dentro dos parâmetros microbiológicos, físicos e químicos de potabilidade e balneabilidade (ALVES FC, et al 2016).

Segundo FILHO FMA e SILVA LM (2008), o termo microrganismo indicador, sugere que a presença desse tipo de organismo evidencie a contaminação daquele recurso hídrico e determine a presença de matéria fecal de origem entérica de humanos e animais homeotérmicos. 
Os bioindicadores são utilizados como forma de avaliar a qualidade da água, a fim de preservá-la. Esses marcadores biológicos são organismos vivos, cujo seu objetivo é indicar a presença de alterações causadas pela poluição que pode causar danos à saúde humana e ao ecossistema (BRASIL, 2004).

Diante disso, o presente estudo tem como objetivo discorrer sobre o uso de bioindicadores do grupo coliformes, evidenciar sua empregabilidade e características ideais para sua utilização.

\section{REVISÃO BIBLIOGRÁFICA}

\section{Histórico da qualidade da água no Brasil}

Como se trata de um recurso limitado, o fornecimento de água vem sendo razão de preocupação a um longo tempo. Avaliando a qualidade desde os mananciais até o abastecimento, acredita- se que a água vem se deteriorando e sofrendo transformações significativas em decorrência de atividades humanas. Fatores socioeconômicos são determinantes no comprometimento da qualidade da água. O crescimento demográfico, desenvolvimento social e econômico, soterramento de encostas, a falta de tratamento de esgotos na rede pública de saneamento, erosão e falta de políticas ambientais, têm colaborado para chegarmos a atual conjuntura (FERNANDES KCB, 2015).

O agravamento no que diz respeito a qualidade da água segue desde a sua fonte, onde ocorre o derramamento de efluentes e rejeitos, até insuficiência de medidas que garantam os padrões necessários de potabilidade resultantes das redes de captação e tratamento, distribuição incapaz e escassez de manutenção no sistema de reservação e distribuição, e por último nos domicílios, no que agrava a situação, visto que além de todos esses elementos, podemos atestar que o sistema hidráulico-sanitário e a ausência de manutenção em reservatórios de muitas residências é precário, e em conjunto com a manipulação incorreta da água, segue comprometendo a qualidade da água fornecida (BRASIL, 2006).

O Brasil há alguns anos, não observava e nem considerava políticas que pretendessem assegurar padrões de potabilidade da água. Porém devido ao colapso na saúde pública, escassez e danos aos recursos hídricos, se fez necessário a criação de documentos que garantissem a distribuição de água de boa qualidade tão como a conscientização e cuidados com esse ecossistema (BRASIL, 2012).

Entre os principais documentos que asseguram e garantem os cuidados e os padrões necessários da qualidade da água estão: a lei № 9.433 de 8 de Janeiro de 1997 que institui a Política Nacional de Recursos Hídricos, criou o Sistema Nacional de Gerenciamento de Recursos Hídricos, tendo como objetivo informar às futuras gerações sobre a necessária disponibilidade da água, seus padrões de qualidade e consumo consciente; Portaria № 518, de 25 de Março de 2004 que estabelece os procedimentos e responsabilidades para o controle e vigilância da água utilizada para consumo; Resolução Conama № 430, de 13 de Maio de 2011 que determina condições e padrões para lançamento de efluentes. É a normativa do Ministério da Saúde que avalia os procedimentos de controle e vigilância da qualidade da água consumida por humanos. A portaria estabelece os padrões de qualidade química, física e microbiológica da água tais como parâmetros necessários para a potabilidade e métodos de avaliação periódica, na garantia de evitar danos à saúde da população. (BRASIL, 2012).

\section{Características Microbiológicas da água}

Os microrganismos inseridos na água em seu aspecto natural, desempenham diversas atividades extremamente necessárias para a manutenção da vida de diversos organismos, como por exemplo a decomposição de matéria orgânica que resulta na formação de outras substâncias simples, pela ação de bactérias (BRASIL, 2006).

Fatores socioambientais que influenciam a degradação de recursos hídricos, por meio de dejetos fecais, podem ser um grande risco para contaminação por microrganismos patogênicos. Considerando a série de problemas, é de extrema importância realizar avaliações periódicas mantendo assim a segurança da qualidade da água e promovendo a saúde pública.

REAS/EJCH | Vol.Sup.34 | e1099 | DOI: https://doi.org/10.25248/reas.e1099.2019 Página 3 de 7 
A qualidade microbiológica da água, usualmente é avaliada pelo uso de bactérias indicadoras. A presença desses microrganismos em grande quantidade pode oferecer danos à saúde além de constatar que aquele recurso hidrográfico esta poluído com matéria de origem fecal (FERNANDES KCB, 2015).

\section{Enfermidades de veiculação Hídrica}

Enfermidade de veiculação hídrica, é toda doença relacionada a água. Desde a contaminação pela ingestão de água contaminada, a falta de padrões de higiene pela escassez e má distribuição. Podemos destacar também infecções por verminoses, embora não sejam transmitidas diretamente pela água, o patógeno utiliza se de meio aquático para sobrevivência. E por fim doenças provocadas por vetores como mosquitos que nascem e picam próximos a corpos d'agua. O Quadro 1 a seguir apresenta uma sinopse das principais doenças de veiculação hídrica (BRASIL, 2006).

Quadro 1 - [principais doenças de veiculação hídrica] - Principais doenças relacionadas a água.

\begin{tabular}{|l|l|}
\hline Fatores de Transmissão & Principais doenças \\
\hline & $\begin{array}{l}\text { Amebíase Ascaridíase Cólera e } \\
\text { giardíase }\end{array}$ \\
Transmissão via fecal-oral & Hepatite infecciosa Leptospirose \\
(Água e alimentos contaminados) & Febre tifoide e paratifoide \\
& Criptosporoidíase \\
\hline \multirow{3}{*}{ Higiene pessoal precária } & $\begin{array}{l}\text { Infecções na pele e nos olhos } \\
\text { Escabiose }\end{array}$ \\
\hline Penetração na pele & Tifo relacionado a piolho \\
\hline \multirow{2}{*}{ Insetos incidentes em areas ribeirinhas } & Esquistossomose \\
& Dengue \\
& Febre amarela Filariose \\
& (Elefantíase) Malária \\
\hline
\end{tabular}

Fonte: Andrade GF, Barros DB, 2019. Adaptado de secretária de vigilância de saúde, 2006; Pereira GF, 2010.

\section{Bioindicadores de poluição fecal}

Habitualmente a presença de microrganismo causadores de doenças, provem da poluição hídrica por fezes de humanos e animais de sangue quente, oriundos de água reincidida. O "Standard Methods for the Examination of Water and Wastewater" define o grupo coliforme como bactérias aeróbias ou anaeróbias facultativas, do tipo Gram negativas, sendo elas não esporuladas e em sua forma de bastonete, as quais fermentam a lactose com formação de gás dentro de $48 \mathrm{~h}$ a $35^{\circ} \mathrm{C}$. Está incluído também organismos que divergem nas características sorológicas e de habitat. Pertencente do grupo coliformes, estão as bactérias do gênero Escherichia coli, Aerobacter, Citrobacter, Klebsiela e outros raramente encontradas em fezes como a Serratia (SOUTO JP, et al, 2015).

As bactérias indicadoras de contaminação fecal, são usadas constantemente na avaliação de qualidade da água. Entretanto a presença de coliformes na água no seu estado bruto, ou no que diz a potabilidadedentro do seu índice permitido pela portaria 2.914/11 do Ministério da Saúde, não implica em contaminação, tendo em vista que bactérias desse grupo são encontradas facilmente difundidas no meio ambiente. Porém a presença de coliformes termotolerantes pode indicar contaminação de origem fecal e a existência de patógenos que se encontram em menores concentrações, toda via que essas bactérias são encontradas em abundancia em fezes de humanos e animais homeotérmicos. (CERQUEIRA MMOP, et al 2006; GODOI I, et al., 2010).

De acordo com FERNANDES KCB (2015) os indicadores podem apresentar limitações, pois ainda existe muita dificuldade de identificar a origem da contaminação fecal pois a incapacidade de distinção do organismo fonte, em vista que esses indicadores são excretados também por animais homeotérmicos. Outra limitação é a utilização desses bioindicadores em regiões de clima tropical, onde esses microrganismos sobrevivem em sedimentos e podem ser encontrados distantes de ambientes habitados, assim inviabilizando a distinção de poluição recente. 
Para Nascimento NRM (2015) bactérias do grupo coliformes, representam cerca de $96 \%$ a $99 \%$ nas fezes, onde cada indivíduo excreta cerca de 2 bilhões rotineiramente. Desta maneira é possível que na pesquisa de outros microrganismos, se obtenha a descoberta de organismos patogênicos incidentes em fezes. A partir disso, a presença destes microrganismos na água, estabelece indicadores de matéria fecal e a aparição de patógenos (AMARAL LA, 1994).

Para garantir a eficácia de indicadores microbiológicos de poluição fecal, os mesmos devem seguir os seguintes fatores: $O$ indicador necessita está presente em grande proporção nas fezes humanas e de animais de sangue quente; estar contido em efluentes residuais e ausentes em água limpa; ser exclusivamente de origem fecal e de fácil reconhecimento; possuir uma nutrição pobre; não se multiplicar na água; necessitam ter mais resistência a agentes desinfetantes comparado a microrganismos patogênicos (FILHO FMA e SILVA LM, 2008).

Bactérias do grupo coliformes totais são usualmente utilizadas na avaliação de condições higiênicas, enquanto o grupo coliforme termotolerantes, indicam uma possível contaminação fecal e deficiência de condições higiênicas sanitárias. As bactérias do grupo coliformes totais, foram consideravelmente utilizadas e segue sendo empregada em outros estudos, porém em decorrência da ausência de bactérias fecais, se tornou um problema. Sendo assim as bactérias do grupo coliformes termotolerantes se tornaram mais eficazes na indicação de poluição fecal, pois se restringe ao trato gastrointestinal de animais homeotérmicos e humanos, desta forma garantindo uma correta avaliação (CERQUEIRA MMOP, 2006).

\section{Coliformes Termotolerantes}

O Ministério da Saúde por meio da Resolução oㅡ 518 de 25 de março de 2004, resignou o termo Coliforme termotolerante como um subgrupo de bactérias do grupo coliforme. Segundo o CONAMA na resolução no $357 / 2005$, as bactérias do grupo coliforme termotolerantes, são bactérias gram negativas, que podem crescer em meios contendo alguns agentes e por sua vez pode fermentar a lactose em media a $45^{\circ} \mathrm{C}$, podendo produzir gás, ácido e aldeído.

Para a associação Americana de saúde pública (APHA), a E coli é comumente aplicada na avaliação de contaminação fecal. Cepas de klebsiella, Enterobacter e citrobacter também manifestam termotolerância, mas não são de exclusividade do trato intestinal humano e de animais homeotérmicos, contudo estão inseridas habitualmente em águas poluídas (RECHE MHLR, et al., 2010) (Tabela 1).

A resolução 357/2005 do Conama, dispõe sobre a classificação dos corpos hídricos e de diretrizes ambientais para seu enquadramento, se utiliza coliformes termotolerantes como padrão de qualidade microbiológica de acordo com critérios estabelecidos pela legislação (CONAMA, 2005).

Tabela 1 - [Padrões permitidos para coliformes] - parâmetros necessários para água de consumo humano.

\begin{tabular}{lll}
\hline Tipo de água & Parâmetro & Volume \\
\hline Água para consumo & Escherichia coli & Ausência $-100 \mathrm{ml}$ \\
& Coliformes totais & Ausência $-100 \mathrm{ml}$ \\
Água tratada & Escherichia coli & Ausência $-100 \mathrm{ml}$ \\
Na saída do tratamento & Coliformes totais & Ausência $-100 \mathrm{ml}$ \\
Sistema de distribuição & Escherichia coli & Ausência $-100 \mathrm{ml}$ \\
(Reservátorios e redes) & Coliformes totais & Ausência $-100 \mathrm{ml}$ \\
\hline
\end{tabular}

Fonte: Fonte: Andrade GF, Barros DB, 2019. Adaptado de Ministério de saúde; Portaria ํㅡ 2.914; 2011

\section{Escherichia Coli}

Segundo o CONAMA e a ANVISA a E.coli pertence à família Enterobacteriaceae, se caracteriza pela ação da enzima B- glicuronidiase. Produz indol a partir do aminoácido triptofano. É a única espécie do grupo coliforme termotolerante cujo o habitat exclusivo é o intestino humano e de animais de sangue quente, onde se ocorrem em densidade elevada. É considerada pela legislação vigente o bioindicador mais usualmente indicado na avaliação de contaminação por matéria fecal. (CONAMA 2005; ANVISA 2004). 
A Escherichia coli é um microrganismo existente na microbiota normal do corpo humano e de animais de homeotérmicos, principalmente no trato gastrointestinal, estando presentes em grandes quantidades em esgotos, efluentes, águas naturais e solos que receberam contaminação recente. É também uma das espécies mais abundantes de coliformes termotolerantes e usualmente vem sendo muito utilizada como indicadora de poluição fecal (PINTO AB e OLIVEIRA AJFC, 2011).

Embora grande maioria das cepas da E.coli não sejam patogênicas, podem ocorrer prejuízos à saúde humana pela disseminação dessa bactéria em outros órgãos. As Cepas patogênicas dessa bactéria podem provocar infecções no trato urinário, sistema nervoso e digestivo de indivíduos humanos, e outras doenças como diarreia e doenças de origem alimentar grave (SCHOLTEN C, 2009). As linhagens de E.coli consideradas patogênicas são: E.coli enteropatogênica clássica (EPEC), E.coli enteroinvasiva (EIEC), E.coli enterotoxigênica (ETEC), E.coli entero-hemorrágica (EHEC) e E.coli enteroagregativa (EAggEC) (SEZERINO PH e BENTO AP, 2005; MARQUEZI MC, 2010).

A E.coli é encontrada raramente em ecossistemas não contaminados por matéria fecal, portanto obtendo mais representatividade que coliformes totais na avaliação da qualidade da água. Das bactérias do grupo coliformes presentes em fezes humanas e de animais, 95\% delas são E.coli, e dentro das bactérias do subgrupo termotolerante. Seu reconhecimento em água é de fácil constatação podendo se adotar técnicas simples e rápidas. Sua sobrevivência é similar aos organismos patogênicos mais comuns. São essas particularidades que tornam a E.coli uma indicadora ideal para avaliar os parâmetros microbiológicos de poluição fecal (MARQUEZI MC, 2010).

\section{CONSIDERAÇÕES FINAIS}

O estudo mostra que o uso de bioindicadores do subgrupo dos coliformes termotolerantes é o mais ideal e usual na avaliação e identificação de poluição fecal pois possui características necessárias para realizar tal função. Sendo a Escherichia coli a bactéria indicadora que mais atende os critérios básicos para essa constatação, pois está inserida em abundancia nas fezes de humanos e animais de sangue quente, fornece respostas mais rápidas e acessíveis e manifesta significativo potencial nessas avaliações.

\section{REFERÊNCIAS}

1. ALVES FC, at el. Análise microbiológica e parasitológica da água utilizada em hospital público do estado de Rondônia. Revista Uningá, Vol. 49, PP 41-43; 2016.

2. AMARAL LA, et al. Avaliação da qualidade higiênico-sanitária da água de poços rasos localizados em uma área urbana: utilização de colifagos em comparação com indicadores bacterianos de poluição fecal. Revista. Saúde Pública, 28 (5):345-8; 1994.

3. BELO VS, et al. Fatores associados à ocorrência de parasitoses intestinais em uma população de crianças e adolescentes, Revista Paulista de Pediatria 30(2):195-201; 2012.

4. BRASIL, Ministério da saúde. Análise de indicadores relacionados à água para consumo humano e doenças de veiculação hídrica no Brasil, ano 2013, utilizando a metodologia da matriz de indicadores da Organização Mundial da Saúde (OMS). Edição 1. Ministério da saúde, Brasília; 2015.

5. BRASIL, Ministério da saúde. Lei № 9.433 de 8 de janeiro de 1997. Institui a Política Nacional de Recursos Hídricos, cria o Sistema Nacional de Gerenciamento de Recursos Hídricos. Diário Oficial da União 9 de janeiro de 1997.

6. BRASIL, Ministério da saúde. Portaria 1469/2000 Controle e Vigilância da Qualidade da Água para Consumo Humano e seu Padrão de Potabilidade. Publicada no Diário Oficial da União n. 59, de 26 de março de 2004, seção 1, p. 266270.

7. BRASIL, Ministério da saúde. Portaria № 2.914 de 12 de dezembro de 2011. Dispõe sobre os procedimentos de controle e de vigilância da qualidade da água para consumo humano e seu padrão de potabilidade. Diário Oficial da união 14 de dezembro de 2011.

8. BRASIL, Ministério da saúde. Plano de Segurança da Água, 1ª edição, Brasília; 2012.

9. BRASIL, Ministério da saúde. Portaria № 518, de 25 de março de 2004. Estabelece os procedimentos e responsabilidades relativos ao controle e vigilância da qualidade da água para consumo humano e seu padrão de potabilidade, e dá outras providências. Diário Oficial da união 26 de março de 2004. 
10. BRASIL, Ministério da saúde. Vigilância e controle da qualidade da agua para consumo humano. [Livro online] Brasília: esplanadas dos ministérios; 2006.

11. BRASIL, Resolução Conama № 430, de 13 maio de 2011. Dispõe sobre as condições e padrões e lançamento de efluentes, complementa e altera a Resolução no 357, de 17 de março de 2005, do Conselho Nacional do Meio Ambiente - CONAMA. Diário Oficial da união 16 de maio de 2011.

12. CERQUEIRA MMOP, et al. Qualidade da água e seu impacto na qualidade microbiológica do leite; Researchgate; 2006.

13. CONFALONIERI U, et al. Água e saúde: Aspectos Globais e nacionais. Academia Brasileira de Ciências. [Revista em Internet]; 2011.

14. DANZE AP, VERCELLINO IS. Uso de bioindicadores no monitoramento da qualidade da água. Revista Revinter, v 11 , n. 01 , p. 100-115; 2018.

15. FERNANDES KCB, Detecção e quantificação de contaminação fecal hospedeiro especifico em águas destinadas ao abastecimento público, Dissertação (Pós-Graduação em Vigilância Sanitária do Instituto Nacional de Controle de Qualidade em saúde). Fundação Oswaldo Cruz, Rio de janeiro; 2015.

16. FILHO FMA, SILVA LM. Avaliações das concentrações de coliformes no afluente e efluente da ETE Goiânia em 2007. Dissertação (bacharelado em engenharia ambiental), Universidade católica de goiás - Goiás; 2008.

17. GODOI I, et al. Indicadores microbiológicos de água e solo. Dissertação (Mestrado); UNIOESTE; Cascavel PR; 2010.

18. GOLVEIA N. Saúde e meio ambiente nas cidades: os desafios da saúde ambiental. Revista Saúde e Sociedade 8(1): 49-51, 1999.

19. GOMES JL; BARBIERI JC. Gerenciamento de recursos hídricos no Brasil e no Estado de São Paulo: um novo modelo de política pública. Projeto de pesquisa em gestão pública. São Paulo: Secretaria da Economia e Planejamento do Estado de São Paulo e Centro Universitário Fundação Escola de Comércio Álvares Penteado (Unifecap), 2003.

20. MARQUEZI MC. Comparação de metodologias para a estimativa do número mais provável (NMP) de coliformes em amostras de água (Dissertação) Universidade de são Paulo Escola superior de agricultura "Luiz de Queiroz”, 2010.

21. NASCIMENTO NRM. Avaliação da qualidade da água superficial do Iguarapé quarto nações ba cidade de Arquimedes - RO. Monografia (tecnologia em gestão ambiental). Faculdade de Educação e Meio Ambiente - FAEMA, 2015.

22. PEREIRA GF. Educação em saúde sobre a potabilidade da água e transmissão de danos de veiculação hídrica em estratégia saúde da família na zona rural. Dissertação (especialização); Universidade federal de minas gerais; 2010.

23. PINTO AB, OLIVEIRA AJFC. Diversidade de microrganismos indicadores utilizados na avaliação Da contaminação fecal de areias de praias recreacionais marinhas: estado atual do conhecimento e perspectivas. O Mundo da Saúde, São Paulo: 2011;35(1):105-114; 2011.

24. RECHE MHLR, et al. Bactérias e bioindicadores de qualidade de água e ecossistemas orizízolas da região sul do Brasil. Revista Oecologia Australis 14 (2): 452-463;2010.

25. RIBEIRO LGG, Rolim ND. Planeta água de quem e para quem: uma análise da água doce como direito fundamental e sua valoração mercadológica. Revista Direito Ambiental e sociedade, v. 7, n. 1, 2017.

26. RIBEIRO JW, ROOKE JMS. Saneamento Básico e sua relação com o meio ambiente e saúde pública. Dissertação (especialização em análise ambiental). Juiz de fora: Universidade de Juiz de Fora; 2010.

27. SCHOLTEN C, Dinâmica temporal da poluição fecal nas águas do córrego rico, manancial de abastecimento da cidade de Jaboticabal- SP, Dissertação (Mestrando em Medicina Veterinária) Universidade Estadual Paulista "Júlio de Mesquita Filho" Faculdade de ciências Agrária e Veterinárias Campus de Jaboticabal - São Paulo; 2009.

28. SEZERINO PH, BENTPO AP. Qualidade da água e controle da poluição (especialização). Universidade federal de santa Catarina departamento de engenharia sanitária e ambiental; 2005.

29. SOUTO JP, et al. População fecal da água: Microrganismos indicadores, VI Congresso Brasileiro de Gestão Ambiental, 2015. 